\title{
Why are Clear Migrant Definitions and Classifications Important for Research on Violence Against (Im)Migrant Women?
}

\author{
Nadia Khelaifat*, Ali Shaw and Gene Feder \\ ${ }^{1}$ School of Social and Community Medicine, Centre for Academic Primary Care, University of Bristol, UK
}

\begin{abstract}
Research on violence against (im)migrant women is emerging, but definitions and classifications of immigrants are not consistent, which makes comparisons within and between countries difficult, if not impossible. This is also problematic when studying abused (im)migrant women's needs and experiences within health care. (Im)migrants are often subsumed under the umbrella terms ethnic minorities, ethnic groups, racial minorities, ethnicity or race, or these terms are used interchangeably. This is partly due to the countries' different historic and political migration trajectories. Although there are similarities between migrants and ethnic minorities (e.g. a shared geographical and cultural heritage), there are also considerable differences (e.g. the act of migrating to another country and, as a consequence, the loss of a social network). An important dimension, which is often neglected when studying migrant women, is the age at migration, which is indicative of the migrant generation a woman belongs to and important since it influences how well she can adjust to a new country, language and culture.

The direction of flow of migration (e.g. South-North vs. North-North) may show how similar the country of origin is to the country of residence (e.g. linguistic proximity between the U.K. and the U.S.) and the different reasons for migration (e.g. work, war; forced vs. voluntary) often affect the legal status. When distinct migrant groups are subsumed and are then compared either with each other, other migrant groups or with non-migrants, this has limitations since it masks heterogeneity. Moreover, domestic violence, being one form of gender violence, needs a broader scope to capture the domestic violence experience of (im)migrant women (e.g. violence committed by extended family members). The following article argues for careful definitions, operalizations, and usage of "migration" and "domestic violence" when conducting research on violence against im(migrant) women to make comparison possible and meaningful.
\end{abstract}

Keywords: Migration; Immigration; Definition; Migrant generation; Age at migration; Operalizations; Domestic violence

\section{Introduction}

"Overall, in much of the debates about ethnicity and immigration as well as gender and VAW [Violence against women], MEM [migrant and ethnic minority] women have been either absent and marginal or more recently constructed and represented in particular ways." (Thiara, Condon and Schröttle 2011, p. 20, [1]).

Research on domestic violence (DV), being one form of gender violence, against (im)migrant women is emerging [1]. However, this is highly politically polarized - while domestic violence is prevalent in all countries and societies irrespective of socio-economic status, ethnicity, religion and culture, DV in (im)migrant and ethnic minority communities is often portrayed as a cultural problem while DV in Western countries is thought to represent individual deviant acts [2]. Feminist researchers, however, propose that all violence against women is rooted in the patriarchal ideas of male ownership over women [3].

Domestic violence is one of the greatest health risks to women and children [4]. Women will seek help for injuries or other health consequences caused by domestic violence, thus the health care sector plays a vital role. Despite this, DV is often hidden in the health care sector [5]. Asking about domestic violence has been likened to opening Pandora's Box as clinicians feel uncomfortable asking women, ineffective and powerless to intervene and also fear offending women [6-9]. For all women affected by domestic violence, there are many barriers to disclosure such as fear of the abuser or repercussions and feelings of shame $[7,8]$.

(Im)migrant women may face a number of vulnerabilities and additional barriers when it comes to domestic violence: Their specific immigration status, lack of language skills and being removed from their social network may make them more likely to experience more severe and more frequent forms of domestic violence, including abuse and coercive control from other adult family members [10-13]. Moreover, migrant women might face difficulties accessing support due to a) language barriers, b) not knowing where to get help, c) being accompanied by relatives to health care professionals and d) expressing their suffering differently $[12,14]$. When migrant women do not speak the language, family members often function as interpreters, which makes the disclosure difficult if not impossible $[14,15]$. On the other hand, health care professionals may fear appearing "racist" or offending women when asking them about domestic violence $[9,16]$. Conversely, migrant women may be assumed to experience DV as it is a part of "their" culture or that the family should be informed about disclosure of domestic violence $[9,16]$.

There are few representative surveys or qualitative studies on violence against (im)migrant women, which include either large

*Corresponding author: Nadia Khelaifat, School of Social and Community Medicine, Centre for Academic Primary Care, University of Bristol, United Kingdom, E-mail: nadia.khelaifat@bristol.ac.uk

Received February 28, 2014; Accepted August 04, 2014; Published August 11 2014

Citation: Khelaifat N, Shaw A, Feder G (2014) Why are Clear Migrant Definitions and Classifications Important for Research on Violence Against (Im)Migrant Women? Arts Social Sci J S1: 008. doi: 10.4172/2151-6200.S1-008

Copyright: (c) 2014 Khelaifat N, et al. This is an open-access article distributed under the terms of the Creative Commons Attribution License, which permits unrestricted use, distribution, and reproduction in any medium, provided the original author and source are credited. 
enough sample sizes and/or adequate migrant classifications; there are also ethical and methodological issues, such as, accessing these women safely, getting informed consent, and conducting interviews in the native languages of (im)migrant women [1,12,17].

To review abused (im)migrant women's needs and experiences within the health care system, we are currently undertaking a systematic literature review of qualitative studies to conduct a qualitative metasynthesis of them. Here we were faced with the challenge of how to search bibliographic databases systematically for "migrant" women. This, in turn, has shaped our thinking about the terms "(im)migration" "ethnic minority women" and also "domestic violence", which will be discussed in this paper. Although this paper will primarily focus on definitions and the search strategy and not on the actual results, a few examples will be given to illustrate the key points.

\section{Migrants or Immigrants - Do They Mean the Same?}

As Anderson and Blinder succinctly put it "definitions affect data" [18], but there is no consensus regarding a single definition of who constitutes an (im)migrant $[19]^{1}$. Consequently, there are many different definitions and data sets and the terms "migrant", "immigrant", as well as, "foreigner" are often used interchangeably [19]. When looking at comparative studies, (im)migrants are often subsumed under the umbrella terms "ethnic minorities", racial minorities, foreigners, or race (e.g. in large-scale surveys). So far, there is no agreed system for classifying migration, race, ethnicity, and culture - particularly across countries $[19,20]$.

Even the use of the term "migration" or "immigration" (or "migrant" or "immigrant" respectively) is not clear: In Latin, migratio means movement and migrāre means to move from place to place, change position or to change one's abode [21]. To immigrate means that a non-national moves to a country to settle, while emigrate means to leave one state to settle in another [21]. These terms are commonly used in biology and sociology. Researchers either use them interchangeably or prefer one over the other. This led one of the authors to question whether this is due to an American English or British English/European preference.

The United Nations' definition emphasizes the time dimension [22], but refers to all people who have migrated as "immigrants":

"An immigrant is a person who moves to a country other than that of his or her usual residence for a period of at least a year (12 months), so that the country of destination effectively becomes his or her new country of usual residence. From the perspective of the country of departure the person will be a long-term emigrant and from that of the country of arrival the person will be a long-term immigrant."

Conversely, an international short-term immigrant/short-term emigrant is defined as: "A person who moves to a country other than that of his or her usual residence for a period of at least 3 months but less than a year (12 months) except in cases where the movement to that country is for purposes of recreation, holiday, visits to friends and relatives, business, medical treatment or religious pilgrimage ${ }^{2}$."

1 In British law, there does not exist a definition of migrants or immigrants, the only distinguishing feature is the "right to abode" in the U.K. (i.e. all British citizens, as well as a small minority of Commonwealth citizens) [18]. People who have not got the right are "subject to immigration control" . However, as the "right to abode" also applies to EU citizens, this distinguishing feature has become blurred and is no longer clear-cut [18].

2 The time dimension leaves it unclear how recently (im)migrated women (i.e. women who have lived in a country for less than 3 months) can be classified. This definition is also problematic in regards, to for example, army personnel who may
The International Organization for Migration (IOM) ${ }^{3}$ uses "migration" as the overall term for either em- or immigration and simply calls its report "World Migration Report"4 [23].

"The term migrant was usually understood to cover all cases where the decision to migrate was taken freely by the individual concerned for reasons of "personal convenience" and without intervention of an external compelling factor; it therefore applied to persons, and family members, moving to another country or region to better their material or social conditions and improve the prospect for themselves or their family" (IOM).

So nowadays the scope of migrants is extended to refugees and asylum seekers. To simplify matters and to adhere to the International Organization for Migration's definition, the term migrants will be used, which covers both long- and short-term migrant women.

\section{Historical and political differences in the use of terms and measurements of migrants and ethnic minorities}

There are different trajectories of migration. While the population of the United States and Canada is formed by in-migration [24] and consists of descendants of European (North-North), Afro-Amerian (South-North) and Hispanic origin (South-North) (and where the first settlers - namely Native American Indians - have become ethnic minorities), Europe until very recently, was forged by out-migration [25]. In post WWII Europe, the rapidly developing economy resulted in large-scale labor migration. For instance, in Western Germany, so-called "Gastarbeiter" (guest workers) were recruited from other neighboring European countries (e.g. Turkey) $)^{5}$. In addition to this form of migration, in the U.K., for instance there also exists a flow of migration from ex-colonies (e.g. South-North). Moreover, migration takes place due to war (e.g. refugees) or family reunification [20]. All these different forms of migration have an impact on migrants' legal status, which, however, falls outside the scope of this paper.

Consequently, migration has a few important dimensions such as: 1) the direction of flow of migration (e.g. South-North vs. NorthNorth), 2) the similarity of country of origin and country of residence (e.g. language, culture, religion, legal and social system), 3) reasons for migration (e.g. war, work; forced, voluntary), 4) the migrant generation/ age at migration, and 5) how people are (consequently) classified including their migrant status. For example, if a female engineer from the U.K. migrates to the U.S. (North-North migration) for work reasons, then the country of origin and the country of usual residence share a common language and are very similar in terms of culture, legal systems and religion, which impact the migration experience and its outcome. If this woman encounters domestic violence she would presumably know better where to seek help than a migrant woman

have lived abroad for a long time and whose children might have also been born abroad, and are consequently migrants [18].

3 "Migration - the movement of a person or a group of persons, either across an international border, or within a State. It is a population movement, encompassing any kind of movement of people, whatever its length, composition and causes; it includes migration of refugees, displaced persons, economic migrants, and persons moving for other purposes, including family reunification". (http://www.iom. int/cms/en/sites/iom/home/about-migration/key-migration-terms-1.html)

4 See: http://www.iom.int/cms/en/sites/iom/home/about-iom-1/history.html: "IOM, or as it was first known, the Provisional Intergovernmental Committee for the Movement of Migrants from Europe (PICMME), was born in 1951 out of the chaos and displacement of Western Europe following the Second World War".

5 Thus in Germany the term migration background is used, which is a defining criterion of official statistics to describe a population composed of migrants and their descendants since 1950 [26]. 
who cannot speak English and is unfamiliar with the overall system and culture. So, putting all migrant women into the same category is potentially misleading. In the following section, migrant generation and age at migration will be discussed.

\section{Migrant generation, age at migration and migration background}

Migrant generation and age at migration are often not considered when studying migrant populations; yet, they reveal whether a person has actually migrated him or herself (i.e. $1^{\text {st }}$ vs. $2^{\text {nd }}$ generation) and the age at migration influences how well an individual can adjust to the new country, language and culture.

When pre-school children aged $0-5$ arrive in the country of migration they usually have no or only little memory of their country of origin; because of their young age, they have not yet learned to read or write their paternal language, and are usually socialized and schooled in the country of migration. They typically learn the "new" language without any accent [27]. Their experiences within and outside education and their adaptive outcomes are therefore very similar to their second generation counterparts [27]. Children who are slightly older (aged 6-12) have learned to speak, read and write their mother tongue at school, but finish their education in the country of migration - so they are most likely to become fluent bilinguals who can flexibly adapt between two worlds $[27,28]$. Rumbaut $(2004,2012)[27,28]$ termed them the " 1.5 migrant generation", because they are half-way between the first and second generation. Adolescents aged 13-17 may arrive with or without their families, and may attend secondary school or, if they are older, immediately start work. Consequently, their experiences and outcomes might be more similar to first generation adults than to their native-born second generation counterparts [28]. Within the second generation there are two subgroups: one consists of children whose parents were both foreign-born, whereas the other consists of children where only one parent was foreign-born and the other one was native-born $[27,28]$. Here, children with only one foreign-born parent usually feel more native than children where both parents were foreign-born. Indeed, Rumbaut [27] found that these children were less likely to report their ethnicity as non-native unless they were asked about the place of birth of their parents ${ }^{6}$

\section{Research Findings on Domestic Violence and Interpersonal Violence against Migrant Women}

Hyman et al. [29] found that recent migrant women from nontraditional source countries (e.g. Asian/African countries who had lived in Canada for less than ten years) experienced less intimate partner violence than migrant women from traditional source countries such as the U.K. (who had lived in Canada for more than ten years). In this study, two heterogenic migrant groups were compared with one another, which not only differed in cultural respects but also in terms of socio-demographic characteristics such as education. A reporting bias due to lack of acculturation might have been responsible for the different rates of partner violence found (while no differences in the rates perhaps existed).

Women with foreign-born parents might be more acculturated and thus more adept at recognizing and revealing partner violence than their foreign-born counterparts [30]. Garcia et al. [31] found highly or

6 Rumbaut classified these children (with one native-born parent) as 2.5 generation, while children born to both foreign-born parents are classified as 2.0 generation. moderately acculturated migrant women or second generation migrant women to be more likely to report partner violence when compared to women with the lowest level of acculturation or the first generation women [32]. In contrast, women of the first generation were more likely to tolerate partner violence - here migrant status was assumed to influence both attitudes towards a) recognizing and b) revealing partner violence [32]. As mentioned in the introduction, the dependent legal status can make migrant women more vulnerable to experience domestic violence $[13,14]$. When migrant, acculturation or migrant status definitions differ considerably between studies, findings cannot be compared and have to be interpreted carefully.

\section{Ethnicity, ethnic minority, race - can these terms be applied to migrants?}

"Race" is often used in the U.S. and North America to refer to ethnic minorities. Yet, "race" is a biological concept, which divides human populations into sub-species according to differences in phenotype/ appearance (e.g. skin color, hair texture) [24,25]. The term "race" is much disputed as there is vast evidence, which indicates that there is as much within genetic difference in one "racial" group as between different "racial groups" [24]. Bhopal [24] calls for cautious use, yet he considers it essential when studying racism. In North America, however, researchers are using "race" in a much broader sense, and thus "ethnicity" and "race" are often used interchangeably or as a hybrid form as in "racial and ethnic minorities" [24].

"Ethnicity" or "ethnic group" is used instead of "race" in Europe, which is due its historic misuse (e.g. in committing genocide). Ethnicity describes much more than physical characteristics such as skin color as it is derived from the Greek word "ethnos", which means "people" or "nation" [24]. Bhopal [24] defines it as "the social group a person belongs, and/or is perceived to belong, as a result of certain shared characteristics, including geographical and ancestral origin, but particularly cultural traditions and language". According to Sohal [33] ethnicity is often used as a politically correct way of referring to race or skin color. In Britain, ethnicity was usually measured by using country of birth as a proxy [24]. However, the country of birth might be the same as the country of residence for second or third and later migrant generations. So if the country of birth is the only criterion for establishing ethnicity, then the ethnic origin is not going to be recorded if subsequent generations are born in the country of residence. Also, minorities, for instance, Kurdish people in Turkey cannot be distinguished using the country of birth as a criterion for establishing ethnicity. Consequently, self-assigned "ethnicity" is often used as a defining indicator $[18,24]$. However, it has certain limitations such as test-retest reliability [27]. Furthermore, there might be variations over time regarding how a person perceives his or her ethnicity which may depend on the level of integration in the host country as outlined earlier [27].

Nationalities or citizenships have also been used as a crude measure to identify migrant populations $[18,25,26]$. Yet, depending on the national contexts of the countries, nationalities are not fixed and can change $[18,26]$. This poses a challenge. Maybe as a result, the (self-) classifications "race" and "ethnicity" have been used in the U.S. and in the U.K respectively to identify people with a migration history [24].

\section{Similarities and differences between migrant women and ethnic minority groups}

So what are the similarities and differences between migrants and ethnic minorities/ethnic groups? The commonality is that the terms 
all relate to migration and resulting changes, which can still persist in subsequent generations (e.g. regarding citizenship, legal status etc.) [26]. The boundaries between migrant and ethnic minority women are blurred. The obstacles faced by ethnic minority women are often also encountered by migrant women. However, while ethnic minority women may also have a distant history of migration such as AfroAmericans and often experience similar problems with regards to racism, discrimination and poverty [26,34], they do differ regarding other factors when compared to (first generation) migrants. Foremost, they often have been living in the country of residence for generations. As a consequence, ethnic minority women usually do not face barriers related to a) separation from their social network, b) language, c) immigration status and d) acculturation, though some still do. Yet as noted previously, not all studies differentiate between ethnic minority and migrant women.

In conclusion, there is a current deficit of clear-cut definitions regarding migrant or ethnic minority women, and first or second generation migrants in studies on violence against migrant women. While barriers experienced by migrant women may at least in some aspects be similar to the ones encountered by ethnic minority women, clear definitions, classifications and adequate sample sizes are a necessary pre-requisite to study and address any divergent needs.

When taking all of the above into consideration, for the systematic literature review, we decided to define first generation migrant women for instance, in the U.K. as women who were a) born outside the U.K. to b) non-British (foreign-born, no British citizenship/nationals) parents and c) who have come to live in the country of residence for various reasons (including asylum seekers and refugees). The duration of stay in the country of residence can be very recent (e.g. they have just arrived, for instance, in Britain) with no upper time limit being set (e.g. a woman from India who has lived in the U.K. since the 1960s or longer). Therefore, our definition conflicts with the UN definition, where the minimum amount of time of long-term/short-term migrants is twelve and three months respectively. Moreover, where possible, we will take the age at migration, country of origin, duration of stay in the country of residence, linguistic proximity, legal status, and other sociodemographic aspects (e.g. education) into account.

\section{Domestic Violence and Migrant Women}

Research on domestic violence may be criticized for not investigating cultural forms. Migrant women may be subject to additional forms of violence, such as isolation and domestic servitude, which may not only be perpetrated by their spouses, but also by their family-in-law (e.g. mother-in-law) and other relatives $[10,13,15]$. Therefore, the context of DV has to be widened as it can happen within and outside the intimate relationship (i.e. abuse by the wider family). Raj et al. [10] investigated intimate partner violence (IPV) and found an interrelationship between abuse by in-laws (e.g. emotional and physical abuse) and intimate partner violence among South Asian women. Perpetrators were often the mother-in-law [10]. Here the gender and power constellations are also operative, but sometimes in a different way than in intimate partner violence [35]. There are various manifestations of domestic violence that are present in some cultures and not others, such as, forced marriage, female genital mutilation (FGM) and so-called honor-related violence (including dowry-related blackmail or even murder when the family of the bride does not pay the dowry). Bui and Morash [36] discovered among Vietnamese migrant women in the U.S. culturally relevant forms of partner violence such as throwing liquids (or turning around dining tables). Yet in surveys, these cultural forms of partner violence are not investigated. For instance, the Conflict Tactic Scale 2 (CTS2) developed by Straus et al. [37] consists entirely of "Western" forms of violence, which are, of course, also found in non-Western countries.

Humphreys et al. [38] argue that a good DV definition is crucial for agencies, and ideally should:

a) be inclusive and acknowledge diversity, b) include different types of abuse (e.g. physical, emotional, sexual etc.), c) recognize diverse experience (e.g. including mother-in-law violence, women in polygamous relationships, female infanticide and sex selection) and d) include gender and interconnected power/control issues. The Home Office in the U.K. defines DV as:

"Any incident or pattern of incidents of controlling, coercive or threatening behaviour, violence or abuse between those aged 16 or over who are or have been intimate partners or family members regardless of gender or sexuality. This can encompass, but is not limited to, the following types of abuse: psychological, physical, sexual, financial, emotional. “[HO, 2012, 39].

This definition therefore includes a) DV between wider family members and b) DV between parents and children over the ages of 16. It also covers a range of experiences specific to BME (Black Minority Ethnic) communities such as mother-in-law to daughter-inlaw violence, forced marriage (FM) and honor-related violence, FGM (female genital mutilation), bride price and dowry-related violence. Yet, while apparently inclusive, it only applies to persons over the age of 16 while there has been evidence of FM happening at an early age [40]. Furthermore, FM and honor-related violence often include wider community members, which, for instance, in mainstream Britain, are not seen as family [40].

\section{Searching for Studies on Migrant Women and Domestic Violence}

In the following, a brief summary of the systematic literature search only relating to the definitions of "migrant" women and "domestic violence" will be given. A more detailed protocol can be found at PROSPERO $^{7}$ : http://www.crd.york.ac.uk/PROSPERO/display_record. asp?ID=CRD42014008718\#.Uw4SQ_1_vh0.

The research question for the systematic literature search was: what are the needs and experiences of migrant women who have previously experienced domestic violence regarding communication within health care? As discussed above, different definitions exist for migrant women and domestic violence as well as health care (Table 1); this made the search challenging as not to overlook any relevant articles while at the same time not generate too many irrelevant titles and abstracts.

As there is no consistent definition of DV, it was decided that the search strategy should contain DV, "partner violence" and alternative synonymous terms and phrases such as "intimate partner violence", "violence", "abuse", or "battered" combined with "domestic", "partner", "spouse" or "wife" to reduce the risk of missing any significant articles". The search terms "migrant" or "immigrant" women were used. It was decided to examine migrant women in OECD (Organization for

7 PROSPERO is an international database of prospectively registered systematic reviews in health and social care.

8 Furthermore, family violence and abuse extending to family members (inlaws) were also used. Yet, these combinations did not generate any substantial findings and were so discarded. 


\begin{tabular}{|ll}
\hline Concept & Search terms/alternative terms/synonyms \\
\hline Domestic violence & $\begin{array}{l}\text { Domestic Violence or Spouse Abuse or Battered Women or Battered Women or Battered Females or Partner Violence or } \\
\text { Intimate Partner Violence or Family Violence }\end{array}$ \\
\hline
\end{tabular}

Immigration or Migration or Human migration or "Emigrants and Immigrants" or Migrant farm workers or "Transients and

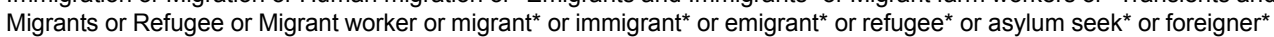

Migrant or country of birth or foreign born or Ethnic groups or ethnic* or Minority groups or minorit* or ethnically diverse or ethnic minorit* or foreign or non-native or black minority ethnic or newcomer* or new-comer* or adoptive citizen* or incomer* or naturali\#ed citizen* or temporary foreign worker* or Vulnerable populations or vulnerable population*

Health care

Health Care or Healthcare or Health Service* or Primary Health Care or Primary Healthcare or Primary Care or Secondary care or secondary healthcare or secondary health care or Tertiary care or tertiary healthcare or tertiary health care or General Practice* or Medical care or Family health care or Family healthcare or Family practice* or Primary Care Nursing or Community Health Nursing or Nursing or Dental facilit* or Preventive Health Service

Table 1: Terms for literature search (abridged overview)

Economic Co-operation and Development) high income countries only and not, for instance, migrants from Thailand in Saudi Arabia. As outlined earlier, much research subsumes migrant women under the term "ethnic minority women". Thus search terms also included "ethnic minority groups", "ethnicity", "ethnic groups" and similar". For example, when looking at the meta-analysis by Feder et al. [7], which investigated the needs and experiences of all women with histories of domestic violence in health care, 29 articles covered 25 studies, of these 23 articles stated that they had included "ethnic minority women" (e.g. Afro-American, but the definitions varied here) or migrants (also numerous definitions given in the studies) while the remaining articles did not specify or state women's ethnicities. This may pose a problem for the inclusion or exclusion of studies (e.g. Humphreys and Thiara ) [41].

When specified, ethnic minority women or migrant women were included to a varying degree ranging from only one ethnic minority/ migrant woman to studies containing migrant women only ${ }^{10}$. The latter applied to three articles $[14,42,43]$, whereby two articles $[42,43]$ referred to the same study. In Robinson and Spilsbury's review [8] of 10 qualitative articles, women's ethnicities were not presented at all, but they cited the same three articles $[14,42,43]$. However, other articles contained a majority or a large proportion of ethnic minority or migrant women [e.g. 44-48]. This posed the question of which studies should be included and what criterion should be applied. It was decided that only when migrant women were a sub-sample for which results were presented separately, these results could be included to examine and identify the specific needs of migrant women.

\section{Conclusion}

It was challenging to search for literature on migrant women affected by DV systematically. Research in this field would be easier to identify and synthesize if we used consistent definitions of the main concepts. Results on migrants should be reported separately - caution should be exerted when subsuming migrant women under the heading "ethnic minorities" unless an overall insight into ethnic minorities is the goal. There is an overall lack of studies for migrant groups specifically with clear-cut migrant or migrant generation definitions. While migrant women's barriers may (at least in some aspects) be similar to the ones encountered by ethnic minority women, precise definitions are an important pre-requisite to address their respective needs.

9 Interestingly, while translating and searching the respective search terms, some databases, e.g. PsycINFO mirror the current use of combining race and ethnicity as their subject heading was "Racial and ethnic groups".

10 However, the sample sizes of these studies varied considerably too.
The contribution of this article is to raise awareness regarding the various terms used for migrant women, to advocate a clearer use and operalization regarding domestic violence and to make research on DV in migrant populations more comparable as well as meaningful.

\section{Authors' Contributions}

NK wrote this article under AH's and GF's supervision as part of her PhD.

\section{Acknowledgement}

Funding statement

NK's studentship is funded by the National Institute for Health Research (NIHR) School for Primary Care Research (SPCR).

\section{Disclaimer}

This review presents independent research funded by the National Institute for Health Research (NIHR). The views expressed are those of the authors and not necessarily those of the NHS, the NIHR or the Department of Health.

\section{References}

1. Thiara RK, Condon S, Schröttle M (2011) Violence Against Women and Ethnicity: Commonalities and Differences Across Europe United Nations' definitions. In R Thiara, M Schröttle, S Condon (Eds) Violence Against Women and Ethnicity: Commonalities and Differences across Europe, Barbara Budrich Publishers, Leverkusen.

2. Chantler K Gangoli G (2011) 'Violence against Women in Minoritised Communities: Cultural Norm or Cultural Anomaly?' In R Thiara, M Schröttle $S$ Condon (Eds) Violence Against Women and Ethnicity: Commonalities and Differences across Europe, Barbara Budrich Publishers, Leverkusen.

3. Johnson MP (1995) Patriarchal Terrorism and Common Couple Violence: Two Forms of Violence against Women. Journal of Marriage and Family 57: 283-294.

4. Krug E, Dahlberg L, Mercy J, Zwi A, Lozano R, et al. (2002) World Report on Violence and Health. World Health Organization: Geneva, Switzerland.

5. Hegarty KL, Gunn JM, O'Doherty LJ, Taft A, Chondros P, et al. (2010) Women's evaluation of abuse and violence care in general practice: a cluster randomised controlled trial (weave). BMC Public Health 10: 2.

6. Sugg N, Inui T. (1992) Primary care physicians' response to domestic violence: Opening pandora's box. JAMA 267: 3157-3160.

7. Feder GS, Hutson M, Ramsay J, Taket AR (2006) Women exposed to intimate partner violence. Archives of Internal Medicine 166: 22-37.

8. Robinson L, Spilsbury K (2008) Systematic review of the perceptions and experiences of accessing health services by adult victims of domestic violence. Health and Social Care in the Community 16: 16-30.

9. Burman E, Smailes SL, Chantler K (2004) 'Culture' as a Barrier to Service Provision and Delivery: Domestic Violence Services for Minoritized Women. Critical Social Policy 24: 332-357.

10. Raj A, Livramento KN, Santana MC, Gupta J, Silverman JG (2006) Victims of 
Citation: Khelaifat N, Shaw A, Feder G (2014) Why are Clear Migrant Definitions and Classifications Important for Research on Violence Against (Im) Migrant Women? Arts Social Sci J S1: 008. doi: 10.4172/2151-6200.S1-008

Page 6 of 6

intimate partner violence more likely to report abuse from in-laws. Violence Against Women 12: 936-949

11. Raj A, Silverman JG (2003) Immigrant South Asian women at greater risk for injury from intimate partner violence. American Journal of Public Health 93: 435-437.

12. Schröttle M, Müller U (2004) Lebenssituation, Sicherheit und Gesundheit von Frauen in Deutschland. Eine repräsentative Untersuchung zu Gewalt gegen Frauen in Deutschland. Bundesministerium für Familie, Senioren, Frauen und Jugend (BMFSFJ): Berlin

13. Hague G, Gangoli G, Joseph H, Alphonse M (2006) Domestic violence, marriage and immigration: if you are immigrating into the UK to marry, what you might need to know. The Violence Against Women Research Group, University of Bristol, Bristol.

14. Belknap RA, Sayeed P (2003) Te contaria mi vida: I would tell you my life, if only you would ask. Health Care for Women International 24: 723-737.

15. Shirke KE, Feder GS, Thorogood N (2009) South Asian women and domestic abuse. A qualitative investigation into south Asian women's experiences of domestic abuse and its perceived impact on their physical and mental health in East London. Centre for Health Sciences, Barts and The London Queen Mary's School of Medicine and Dentistry, London (unpublished).

16. Puri S (2005) Rhetoric v. reality: The effect of 'multiculturalism' on doctors' responses to battered South Asian women in the United States and Britain. Patterns of Prejudice 39: 416-30.

17. Martinez M, Schröttle M et al. (2007): Perspectives and standards for good practice in data collection on interpersonal violence at European level CAHRV - Report 2007. Co-ordination Action on Human Rights Violations funded through the European Commission, 6th Framework Programme, Project No. 506348. Osnabrück.

18. Anderson B, Blinder S (2013) Who counts as a migrant? Definitions and their consequences. Briefing, The Migration Observatory at the University of Oxford.

19. International Organization for Migration (IOM) (2011) Glossary on Migration, International Migration Law Series No. 25, International Organization for Migration, Geneva, Switzerland.

20. Aspinall PJ (2007) Approaches to develop an improved cross-national understanding of concepts \& terms relating to ethnicity and race. International Sociology 22: 41-70.

21. Collins English Dictionary and Thesaurus (1993) Managing Editor: Marian Makins, Haper Collins Publisher, Glasgow.

22. United Nations. http://unstats.un.org/unsd/demographic/sconcerns/migration/ migrmethods.htm

23. World Migration Report Migrant Well-being and development (2013) International Organization for Migration, Geneva, Switzerland.

24. Bhopal R (2004) Glossary of terms relating to ethnicity and race: for reflection and debate. Journal of Epidemiology Community Health 48: 441-445.

25. Bhopal $R$ (2012) Research agenda for tackling inequalities related to migration and ethnicity in Europe. Journal of Public Health 34: 167-73.

26. Schenk L, Bau AM, Borde T, Butler J, Lampert T, et al. (2006) Mindestindikatorensatz zur Erfassung des Migrationsstatus. Empfehlungen für die epidemiologische Praxis, Bundesgesundheitsblatt- Gesundheitsforschung - Gesundheitsschutz, 4: 853-860.

27. Umbaut RG (2004) Ages, Life Stages, and Generational Cohorts: Decomposing the Immigrant First and Second Generations in the United States. Internationa Migration Review 38: 1160-1205.

28. Rumbaut R (2012) Generation 1.5, educational experiences of. In J. Banks (Ed.), Encyclopedia of diversity in education.Thousand Oaks, CA: SAGE Publications.

29. Hyman I, Forte T, Du Mont J, Romans S, Cohen MM (2006) The association between length of stay in Canada and intimate partner violence among immigrant women. Amercian Journal of Public Health 96: 654-659.

30. Lown EA, Vega WA (2001) Prevalence and predictors of physical partne abuse among Mexican American women. American Journal of Public Health 91: 441-442

31. Garcia L, Hurwitz EL, Kraus JF (2004) Acculturation and reported intimate partner violence among Latinas in Los Angeles. Journal of Interpersonal Violence 20: 569-590.

32. Barata PC, McNally MJ, Sales IM, Stewart DE (2005) Portuguese immigran women's perspectives on wife abuse: a cross-generational comparison Journal of Interpersonal Violence 20: 1132-1150.

33. Sohal A (2011) Identifying intimate partner violence in different ethnic groups in primary care - a systematic review and secondary data analysis. [Thesis for the degree of Doctor of Medicine (Research)]. Queen Mary, University of London, London.

34. Bent-Goodley TB (2007) Health Disparities and Violence Against Women: Why and How Cultural and Societal Influences Matter, Trauma Violence Abuse 8: 90-104.

35. Gangoli G, Rew M, Gill A (2013) 'Violence between Female In-laws in India'. Journal of International Women's Studies 14: 147-160.

36. Bui HN, Morash M (1999) Domestic violence in the Vietnamese immigran community. Violence Against Women 5: 769- 795.

37. Straus MA, Hamby SL, Boney-McCoy S, Sugarman DB (1996) The revised Conflict Tactics Scales (CTS2): development and preliminary psychometric data. Journal of Family Issues 17: 283-316.

38. Humphreys C, Hester M, Hague GM, Mullender A, Abrahams HA, et al.(2000) Working with Families where there is Domestic Violence. JRF Findings.

39. Home Office domestic violence definition (2013) HM Government.

40. Gangoli G, Razak A, McCarry M (2006) Forced Marriages and Domestic Violence among South Asian Communities in North East England. Newcastle and Bristol: Northern Rock Foundation and University of Bristol.

41. Humphreys C, Thiara R, (2003) Mental health and domestic violence: 'I call it symptoms of abuse". British Journal of Social Work 33: 209-226.

42. Bauer HM, Rodriguez MA, Szkupinski Quiroga S, Flores-Ortiz YG (2000) Barriers to Health Care for Abused Latina and Asian Immigrant Women. Journal of Health Care for the Poor and Underserved 11: 33-44.

43. Rodriguez MA, Bauer HM, Flores-Ortiz Y, Szkupinski-Quiroga S (1998) Factors affecting patient-physician communication for abused Latina and Asian immigrant women. The Journal of Family Practice 47: 309-311.

44. Battaglia T, Finley E, Liebschutz J (2003) Survivors of intimate partner violence speak out: Trust in the patient-provider relationship, Journal of General Internal Medicine. 18: 617-623.

45. Chang JC, Decker M, Moracco KE, Martin SL, Petersen R, et al.(2003) What happens when health care providers ask about intimate partner violence? A description of consequences from the perspectives of female survivors. Journa of the American Medical Women's Association 58: 76-81.

46. Bacchus L, Mezey G, Bewley S (2002) Experiences of seeking help from health professionals in a sample of women who experienced domestic violence. Health and Social Care in the Community 11: 10-18.

47. Yam M (2000) Seen but not heard: battered women's perceptions of the experience, Journal of Emergency Nursing 26: 464-470.

48. Rodriguez MA, Quiroga Szkupinski S, Bauer HM (1996) Breaking the silence. Battered women's perspectives on medical care, Archives of Family Medicine 5: 153-158.

This article was originally published in a special issue, Violence Agains Immigrant Women: A Global Perspective Throughout the Life-Cycle handled by Editors. Nawal H. Ammar, University of Ontario Institute of Technology (UOIT), Canada; Arshia U. Zaidi, University of Ontario Institute of Technology (UOIT), Canada 